\title{
Collaborative Innovation of Low-Carbon Technology from the Triple Helix Perspective: Exploring Critical Success Factors Based on DEMATEL-ISM
}

\author{
Herui Cui, Xianfei Zhu*, Huange Wang \\ School of Economics and Management, North China Electric Power University, Baoding, China
}

Received: 7 December 2018

Accepted: 29 May 2019

\begin{abstract}
Nearly 200 countries signed the Paris Agreement at the end of 2015 in order to cope with the crisis caused by global warming. $95 \%$ of the possibility is that $\mathrm{CO}_{2}$ emitted from human activities causes global warming. Therefore, encouraging enterprises to carry out low-carbon technology innovation, which can help enterprises reduce $\mathrm{CO}_{2}$ emissions in the production process, is one of the most effective ways to control the greenhouse effect from the source. Due to the limitations of the industry's own research and development (R\&D) capabilities, the cooperation innovation of low-carbon technology in industryuniversity-research-government (IURG) is the most feasible solution. This paper uses the combination of the Decision-Making Trial and Evaluation Laboratory (DEMATEL) and interpretative structural modelling method (ISM) to explore the influencing factors of collaborative innovation in low-carbon technology. The results of the model show the relationship between the 13 factors of economic interest, management and macro environment affecting the collaborative innovation of low-carbon technologies in IURG. The social low-carbon awareness and culture and industry low-carbon value awareness have been innovatively proposed, which has had a neglected impact on the research issues. The research in this paper can effectively improve the diffusion efficiency of low-carbon technology in China, with a view to helping achieve the Paris Agreement goals.
\end{abstract}

Keywords: IURG cooperation, low-carbon technology, influencing factors, DEMATEL-ISM

\section{Introduction}

Human beings have made great progress in the past half century, which has greatly improved the

*e-mail: 1057647496@qq.com living conditions of human beings, but at the same time, the ecological environment has also been greatly damaged. The above situation is more obvious in China [1]. Climate change has become one of the most serious challenges that the world needs to face today. In May 2018, in a speech at the Tsinghua Forum and Climate Change Lecture Hall, Mr. Xie, China's Special Representative for Climate Change, said that climate 


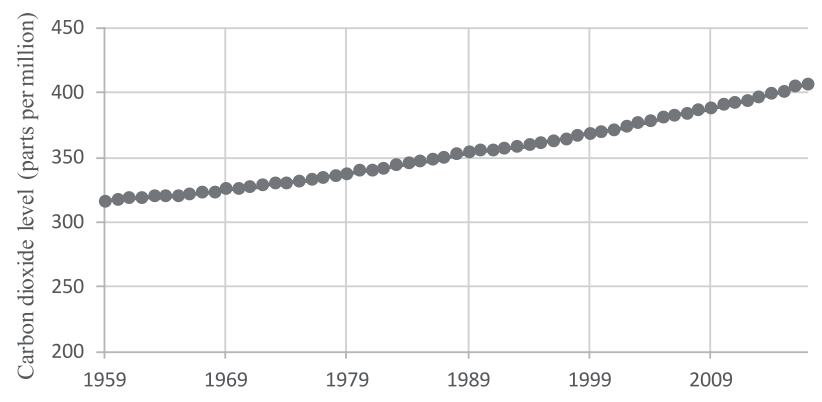

Fig. 1. Trend of carbon dioxide content in the atmosphere.

change is a major challenge facing humanity all over the world. Addressing climate change is an inherent need for China's sustainable development. Before the start of the first industrial revolution, the concentration of carbon dioxide in the air was below $300 \mathrm{ppm}$ (or parts per million, which represents the average number of carbon dioxide molecules in a million air molecules) [2]. As can be seen from Fig. 1, the amount of carbon dioxide in the atmosphere has been increasing since 1959. At the same time, in 2015 new research published in Nature confirmed the thermal capture of carbon dioxide. Moreover, the fifth report of the IPCC (Intergovernmental Panel on Climate Change) concluded that human activities are have been highly likely (more than $95 \%$ of the possibilities) to lead to the global greenhouse effect since the 1950s. Researchers say that global warming is one of the most serious environmental disasters for the human living environment [3].

As the world's largest emitter, China already has accounted for $27.6 \%$ of global carbon emissions in 2017 [4-5]. Dong et al. demonstrated that the industrial sector is the key sector of energy by decomposing the driving force of carbon dioxide emission intensity (CEI) per unit GDP of China from 1992 to 2012, and that energy efficiency contributes the most to CEI reduction, and different stages of urbanization have different impacts on carbon emissions [6-8]. Meanwhile, China's industry, as a major contributor to carbon emissions, will continue to play its role in the coming decades [9]. Therefore, encouraging industrial enterprises to carry out lowcarbon technology innovation is one of the most effective ways to control the greenhouse effect from the source [10]. On the one hand, as a demand side of low-carbon technology innovation, the secondary industry with high energy consumption cannot overturn the traditional high-carbon-dependent production mode because of its weak R\&D capability, which greatly hinders the development of China's low-carbon economy. On the other hand, universities and other scientific research institutions have strong professional R\&D teams, but, because of the insensitivity to market demand, the ability to transform scientific research results is limited. At the same time, the government needs low-carbon technological innovation in order to speed up industrial transformation, improve the living environment of the nation and achieve emission reduction targets, but it is limited by its own lack of professionals. That is to say, low-carbon technology innovation is difficult and cannot achieve a rapid breakthrough by relying solely on unilateral resources. At present, there are abundant research results on South-South technology transfer cooperation and North-South technology transfer cooperation between the international related fields [11-12]. From the perspective of domestic multi-party participation in low-carbon technology innovation, the collaborative innovation model makes the participants complement each other's disadvantages and combine their advantages to give full play to the systematic synergistic effect, effectively promoting the development of China's low-carbon economy, control the emission of carbon dioxide and other greenhouse gases, and then delay the process of global warming.

This paper believes that the synergy between IURG can accelerate the progress of China's low-carbon technology, the transformation of results. Low-carbon technology can be used in the industry and optimized in practice. Thus, low-carbon technology can better serve China's industrial upgrading. Of course, the process of collaborative innovation between IURG is unlikely to be smooth. There are bound to be some positive and negative factors that influence the progress of collaborative innovation in IURG. The purpose of this paper is to carefully explore these influencing factors and to study the relationship between these influencing factors. In the end, the research proposes countermeasures to promote the process of collaborative innovation of low-carbon technologies in China's IURG.

\section{Material and Methods}

\section{IURG Collaboration System}

Collaborative innovation was first proposed by the American scholar Peter Gloor, who believes that collaborative innovation is based on common goals and mutual encouragement. With the support of network technology platform, cooperative teams can exchange knowledge and ideas instantly and control the project schedule at any time. In addition, collaborative innovation is an innovative behavior across departments, organizations and systems. Significantly, collaborative innovation breaks through the information asymmetry between subjects, effectively integrating innovation elements with resources, fully releasing all subjects' innovative elements such as capital, talents, knowledge and technology, and thus realizing in-depth cooperative innovation.

The Triple Helix Theory Model (THTM) was originally proposed by Henry Etzkowitz of the United States and Professor Loet Leydesdorff of the Netherlands in 1996. As shown in Fig. 2 ("University" also represents universities and research, the same below) as an innovation theoretical model developed rapidly in recent years, THTM breaks through the 

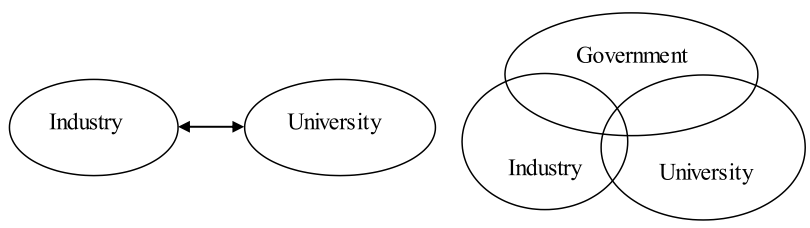

Fig. 2. Evolution of Traditional IUR Model to Triple Helix Model.

double-helix linear structure of "industry-university" in the previous IUR theory and gradually evolves to the triple-helix nonlinear network innovation model of IURG. In this model, the government, universities and industry communicate closely, interacting and influencing each other in the process of innovation. Finally, a new "triple helix" relationship is formed between the three main bodies as shown in Fig. 3. Introducing the theoretical model into the collaborative innovation of low-carbon technologies, it is effectively to promote China's industrial upgrading and achieve emission reduction targets as soon as possible.

The three-helix spiral shows an evolutionary form: each spiral is constantly improving and seeking its own development. This forms a longitudinal evolution of the triple helix. This cycle is formed by several elements, including people, information and products, forming a cycle of personnel, information and capital circulation [13]. A university mainly provides high-quality graduates, new scientific research results and new ideas; the products of industry include commodities, taxes and capital; the main responsibility of the government is to establish and improve credit systems, including policies and regulations, and provide subsidies.

\section{Status Quo of IURG Collaborative Innovation of Low-Carbon Technology in China}

As the economy continues to evolve and change, new technologies, new products and new ideas constantly emerge, and collaborative innovation has become
Table 1. Expenditure on R\&D in some regions of China. Unit: CNY 100 million

\begin{tabular}{|c|c|c|c|c|}
\hline & 2013 & 2014 & 2015 & 2016 \\
\hline Guangdong & 1443.5 & 1605.4 & 1798.2 & 2035.1 \\
\hline Jiangsu & 1487.4 & 1652.8 & 1801.2 & 2026.9 \\
\hline Shandong & 1175.8 & 1304.1 & 1427.2 & 1566.1 \\
\hline Beijing & 1185 & 1268.8 & 1384 & 1484.6 \\
\hline Zhejiang & 817.3 & 907.9 & 1011.2 & 1130.6 \\
\hline Shanghai & 776.8 & 862 & 936.1 & 1049.3 \\
\hline Hebei & 281.9 & 313.1 & 350.9 & 383.4 \\
\hline Ningxia & 20.9 & 23.9 & 25.5 & 29.9 \\
\hline Hainan & 14.8 & 16.9 & 17 & 21.7 \\
\hline Qinghai & 13.8 & 14.3 & 11.6 & 14 \\
\hline Tibet & 2.3 & 2.4 & 3.1 & 2.2 \\
\hline
\end{tabular}

a concern of scholars and governments in various countries. However, due to the fact that the THTM is not yet mature in China, the legal policy formulation and other aspects are still not comprehensive, so the problems and contradictions in the process of collaborative innovation are gradually emerging [14].

\section{Insufficient Investment in R\&D Funds}

At present, R\&D input intensity is an objective and reasonable evaluation index to measure a country's scientific and technological investment level. In 2017, China's R\&D input intensity reached $2.12 \%$ - up $0.01 \%$ from the previous year and already exceeded the average level of $2.08 \%$ in the $15 \mathrm{EU}$ countries, but there is still a big gap compared with innovative countries, such as Israel (4.25\%), South Korea (4.23\%) and Japan (3.49\%). According to China's National Medium- and Long-Term Science and Technology Development Plan (2006-2020), China's R\&D investment will reach 2.5\%

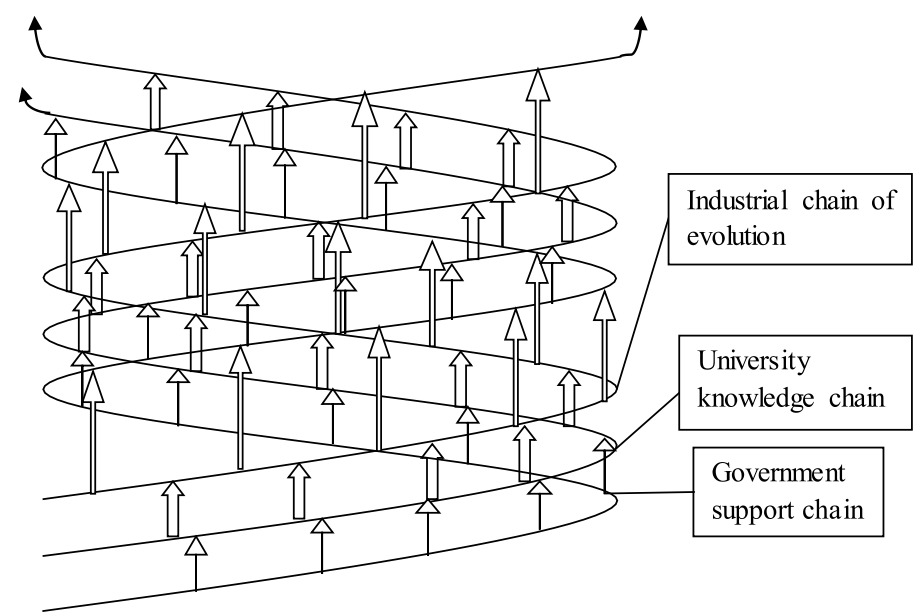

Fig. 3. Interactive Evolution of Three Chains in Triple Helix. 
by 2020 . There are still difficulties in achieving this goal on schedule.

\section{Uneven Distribution of $R \& D$ Funds}

According to the 2016 China Statistical Yearbook data, R\&D spending in eastern China is CNY 10689.04 billion, while R\&D spending in central, western and northeastern China is CNY 2378.81 billion, CNY 1944.03 billion and CNY 6649 billion respectively. The total amount is less than CNY 5000 billion - less than half of that in eastern China. Table 1 shows the imbalance of R\&D input distribution in different regions of China.

\section{$R \& D$ Achievements Have not Been Fully Transformed}

As can be seen from Fig. 4, the number of patent applications for inventions has increased significantly since 2014, indicating that China's R\&D innovation achievements have been increasing, but the number of scientific and technological achievements registered has remained stable and has not increased significantly. In other words, most of the scientific research results have not been put into commercial practice. This reflects the serious challenge of low-carbon technology innovation in China and how the ability to transform results is insufficient.

\section{The Principle of Benefit Distribution is not Perfect}

In the process of collaborative innovation, on the one hand, due to the limited rationality of the collaborative subject and the different purposes of various stakeholders, opportunism will inevitably occur in the process of collaborative innovation. However, now there is no reasonable supervision and punishment

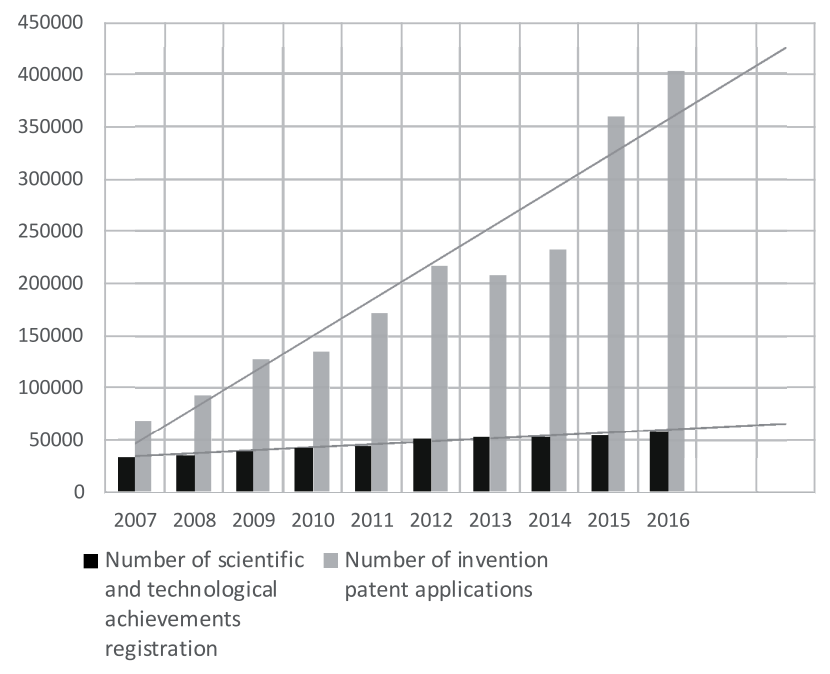

Fig. 4. Scient ific and Technological Achievements Regis tration Number of Invent ion Patent Applicat ions. mechanism. On the other hand, the intellectual property issue after the success of collaborative innovation can always cause the breakdown of the cooperative relationship. Therefore, whether the distribution of interests is fair and reasonable is a sensitive factor that affects the success of the collaborative innovation of IURG.

\section{Literature Review}

After development, the industry-university-research institute formed a complex system in which the government and users have also joined [15]. However, this paper studies low-carbon technology, and the users of low-carbon technology are industries. So, we only need to study the system of low-carbon technological cooperation innovation in which four subjects participate.

Wang et al. (2018) constructed static and dynamic spatial econometric models and analyzed the spatial correlation between regional innovation performance and IUR cooperation innovation based on China's provincial data [16]. Zhao et al. (2017) established a theoretical model describing the evolution of IUR cooperative innovation system by understanding the evolution of China's cooperative innovation system, revealed the mechanism of China's cooperative innovation and the interaction among various elements in the system, and discovered the problems existing in the cooperative innovation process [17]. Feng et al. (2018) proposed to promote technological innovation by strengthening the cooperation between government, industry, university, research and customers in view of the current problems in China's manufacturing industry, and put forward a number of suggestions to promote the development of China's manufacturing industry [15].

Albats et al. (2018) has identified a common set of evaluation indicators in the life cycle of the triple helix cooperation project from the micro level for universityindustry cooperation projects in Finland and Russia [18]. Miller et al. (2018) improved the triple helix model by adding innovative users based on society as the fourth helix, and conducted a literature review of the university technology transfer system from the perspective of the quadruple helix [19]. According to the case study of Nuevo Leon in Mexico, Villasana (2011) found that university researchers were both inspired by the social impact of their research and also driven by the economy [20]. Moreover, the motivation model of researchers are important for the better design of policies aimed at promoting the coordinated development of the triple helix.

One key to promoting the cooperative innovation of IURG is to find the influencing factors and analyze the relationship between them.

Using Community Innovation Survey data for Belgium, Veugelers et al. (2005) considered the overall innovation strategy of enterprises and the influence of other R\&D strategies, analyzed and obtained the 
positive influence factors on the collaborative innovation of the IUR [21]. Agustí et al. (2008), based on the R\&D cooperation data of 4150 innovative enterprises in Spain, determined that the decisive factors of $R \& D$ cooperation innovation between enterprises and universities are obtained by comprehensive analysis [22]. The results also indicate that the success of IURG collaborative activities is closely related to industry characteristics and company characteristics. These include R\&D intensity, scale, process innovation, and whether access to public funds is available for R\&D activities.

Qiu et al. (2016) think that the factors influencing the cooperative innovation of the IUR are mainly divided into three levels: main interests, external support and auxiliary organizations [23]. According to these three levels, the author put forward reasonable suggestions according to these three levels in order to study and discuss how to improve the innovation efficiency of the IUR.

In general, most of the studies have only analyzed the impact of various factors on the collaborative innovation of IURG in a more general way. However, the state's assistance measures and policy setting need to be targeted at key factors. So, it is necessary to understand the status of all kinds of influencing factors in the overall framework and the relationship among these factors. Therefore, this paper will comprehensively consider the impact of low-carbon technology and low-carbon economy, use the integrated DEMATELISM, find out the impact factors of the collaborative innovation of IURG in production, and build a multilevel hierarchical structure model of the impact factors.

\section{DEMATEL-ISM Method Integration}

DEMATEL and ISM belong to the system structure modeling method, both of which use a matrix to analyze the relationship between any two factors in the system. On the one hand, the comprehensive influence matrix in DEMATEL algorithm is easy to calculate and can obtain more valuable information, such as influence intensity information among factors and factor self-reliance information. On the other hand, the calculation results of reachability matrix in ISM can be used to construct the system structure diagram, although the calculation of the reachability matrix is more complicated [24]. After integrating the above two methods, the research results are very rich. Chang et al. (2016) use the integration method of DEMATEL and ISM to analyze the comprehensive influence degree, centrality degree and cause degree of each element of the enterprise internal control system, and get the hierarchical relationship among the elements of the internal control system [25]. Qin et al. (2018) uses DEMATEL-ISM method to find out the key factors affecting the logistics outsourcing risk and draw an intuitive hierarchy chart and find out the root causes of influencing the logistics outsourcing risk [26]. Shen et al. (2014) proposed a system failure analysis model [27]. The logical relationship diagram showing many fault subsystems can be obtained through the integrated DEMTTEL-ISM methods. It shows that this method can be effectively applied to system fault analysis. Shen et al. (2018) take the distributed natural gas-combined cooling, heating and power (DNG-CCHP) which is a supply mode of natural gas as the research object, adopt the integrated DEMTTEL-ISM method to construct a multi-level structure of the factors influencing the economy of DNG-CCHP, and put forward some policy suggestions to promote China's energy transformation and realize the development of green energy [28]. At present, the integrated DEMATEL-ISM has been widely used in various related fields, such as enterprise management, to solve the cause-and-effect relationship analysis

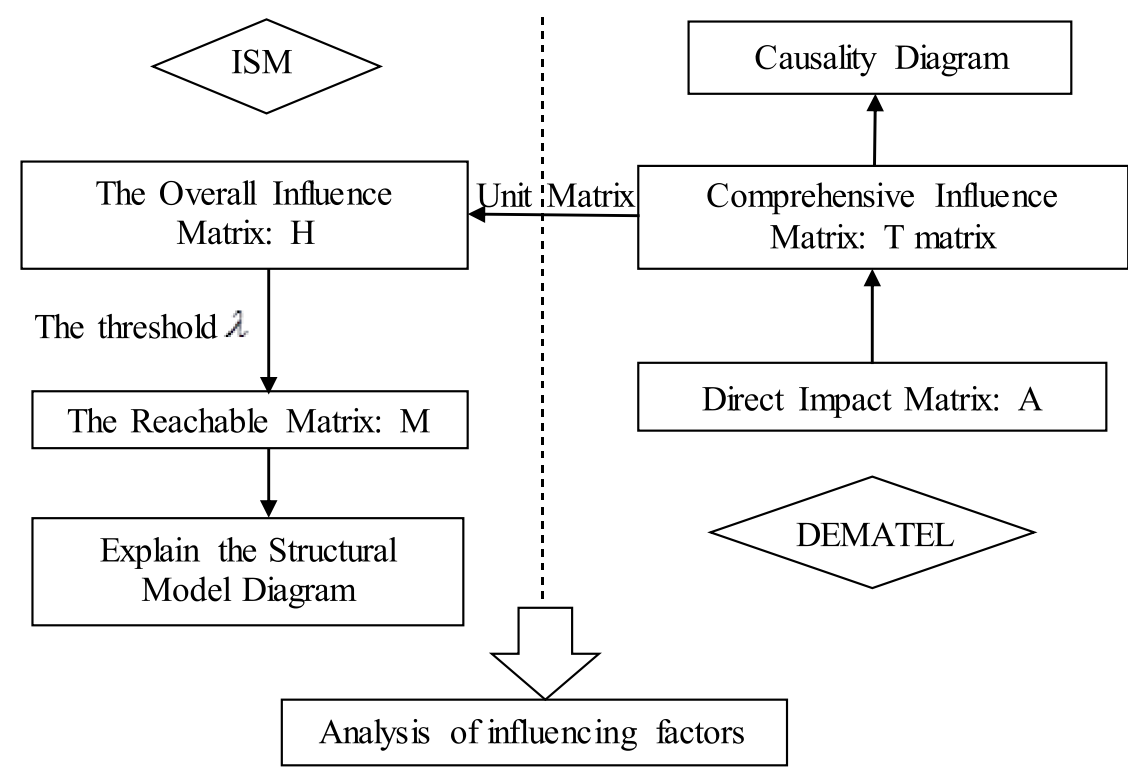

Fig. 5. Brief Process of DEMATEL-ISM Integration. 
between economic, social and technical factors affecting complex systems. Therefore, this paper will also analyze the influencing factors of the cooperative innovation of low-carbon technology in IURG by combining the two methods.

The flow of the DEMATEL-ISM integration method is shown in Fig. 5. The overall impact matrix is obtained by synthesizing the impact matrix, and the overall impact matrix is used to replace the reachable matrix to divide the hierarchy of complex systems. Both methods have their own advantages. DEMATEL focuses on the factors of cause and result of the system, and can identify the key factors and impact degree of complex systems. ISM focuses on the establishment of hierarchical relationships among system elements, which can identify the fundamental elements of the system and the complex hierarchical network relationships among the elements [29]. However, ISM can overcome the

Table 2. Influencing factors and explanations of cooperative innovation of low-carbon technology of IURG.

\begin{tabular}{|c|c|c|}
\hline & Influence factor & Explanations \\
\hline \multirow{3}{*}{$\begin{array}{l}\text { Economic } \\
\text { Interest }\end{array}$} & $\begin{array}{l}\text { Synergetic Income Distribution } \\
\text { (S1) }\end{array}$ & $\begin{array}{l}\text { Unreasonable distribution of cooperative benefits will seriously undermine } \\
\text { the enthusiasm of both sides and hinder the development of cooperative innovation } \\
\text { system [32]. }\end{array}$ \\
\hline & Risk Sharing Mechanism (S2) & $\begin{array}{l}\text { Innovation projects often face huge risks due to their great uncertainty, } \\
\text { and determining a scientific and reasonable risk sharing mechanism must be a key } \\
\text { concern in the collaborative innovation of low-carbon technology. }\end{array}$ \\
\hline & $\begin{array}{l}\text { Degree of Commercialization of } \\
\text { Research Results (S3) }\end{array}$ & $\begin{array}{c}\text { Whether we can transfer knowledge efficiently, absorb and transform new } \\
\text { technologies quickly and commercialize scientific and technological achievements } \\
\text { is an important factor that affects whether cooperative innovation can proceed } \\
\text { smoothly [33-34]. }\end{array}$ \\
\hline \multirow{3}{*}{ Management } & $\begin{array}{l}\text { Resource Sharing and } \\
\text { Information Exchange (S4) }\end{array}$ & $\begin{array}{l}\text { Frequent and effective communication and resource sharing can strengthen } \\
\text { the cooperation and trust of all participants [35-36]. }\end{array}$ \\
\hline & $\begin{array}{l}\text { Relations between R\&D Team } \\
\text { and Other Subjects (S5) }\end{array}$ & $\begin{array}{l}\text { R\&D team is the main body of innovation in university scientific research institu- } \\
\text { tions. The relationship between organization and team also affects the coordination } \\
\text { of innovation technology. }\end{array}$ \\
\hline & $\begin{array}{l}\text { Contract Breach Punishment } \\
\text { (S6) }\end{array}$ & $\begin{array}{c}\text { Mutual trust is an important basis for the stable operation of the cooperative } \\
\text { innovation system of IURG, but the participants will still have speculative behavior } \\
\text { considering their own risks and immediate interests. If a party breaches } \\
\text { the contract, it will be severely punished [37]. }\end{array}$ \\
\hline \multirow{7}{*}{$\begin{array}{c}\text { Macro } \\
\text { Environment }\end{array}$} & $\begin{array}{l}\text { National Environmental } \\
\text { Regulation (S7) }\end{array}$ & $\begin{array}{l}\text { Through the establishment of mandatory standards to control energy consumption } \\
\text { and carbon emissions, and urge enterprises to innovate in low-carbon technologies. }\end{array}$ \\
\hline & $\begin{array}{l}\text { Financial Institution Funds } \\
\text { Support (S8) }\end{array}$ & $\begin{array}{l}\text { Financial intermediaries have strong financial strength and can solve a big } \\
\text { challenge to the financing difficulties of collaborative innovation subjects, so that } \\
\text { excellent low-carbon technology innovation projects will no longer be forced to } \\
\text { terminate due to lack of funds. }\end{array}$ \\
\hline & $\begin{array}{l}\text { Intermediary Related Services } \\
\text { (S9) }\end{array}$ & $\begin{array}{l}\text { The existence of intermediary organizations can make information and funds flow } \\
\text { smoothly among the cooperative innovation subjects, which will affect the success } \\
\text { or failure of low-carbon technology innovation [38]. }\end{array}$ \\
\hline & $\begin{array}{l}\text { Government Policy Support } \\
\text { (S10) }\end{array}$ & $\begin{array}{c}\text { By increasing government subsidies, we can stimulate the enthusiasm of } \\
\text { cooperative innovation of IURG. Design policy support, improve platform } \\
\text { construction and mechanism construction, and help enterprises, universities and } \\
\text { research institutes reduce risks [39]. }\end{array}$ \\
\hline & $\begin{array}{l}\text { Legal and Regulatory } \\
\text { Soundness (S11) }\end{array}$ & $\begin{array}{l}\text { The restriction of laws and regulations is an important guarantee for low-carbon } \\
\text { technological innovation, which can effectively protect the relevant interests of the } \\
\text { industry, university and research institute, and is conducive to the healthy and } \\
\text { lasting operation of the collaborative innovation system [40]. }\end{array}$ \\
\hline & $\begin{array}{c}\text { Low Carbon Consciousness and } \\
\text { Culture (S12) }\end{array}$ & $\begin{array}{l}\text { By vigorously promoting low-carbon culture, spreading and cultivating people's } \\
\text { green concept of low-carbon culture and life, and creating a good atmosphere are } \\
\text { conducive to mobilizing enterprises' enthusiasm for low-carbon technology } \\
\text { innovation. }\end{array}$ \\
\hline & $\begin{array}{l}\text { Enterprise's Value of Low } \\
\text { Carbon Technology Innovation } \\
\text { (S13) }\end{array}$ & $\begin{array}{l}\text { If enterprises want to win in the trend of times development, they must cater to the } \\
\text { national low-carbon development policy. The decision-making level should fully } \\
\text { recognize the important position of low-carbon technology innovation in enterprise } \\
\text { competition, so that the whole enterprise can establish the value concept of } \\
\text { low-carbon innovation. }\end{array}$ \\
\hline
\end{tabular}


defect that only the mutual influence among the factors can be expressed in DEMATEL's method and cannot reflect the influence of the factors themselves. The DEMATEL-ISM method is more oriented to practical application problems to fuse and innovate algorithms, truly realize complementary advantages between algorithms, and embody stronger application value in management practice [30].

The structural model obtained according to the DEMATEL-ISM method not only reveals the importance of each influencing factor, but also comprehensively shows the complex correlation and the path of mutual influence among each factor, and identifies the cause factor and the result factor. Clear structural analysis will effectively promote the further development of cooperative innovation of low-carbon technology in the IURG.

\section{Results and Discussion}

Step 1: Find and determine the set of influencing factors.

Through consulting relevant books, studying relevant literature and combining the experience of predecessors, this paper summarizes the influencing factors of the synergetic innovation system of IURG technology from three aspects and 11 influencing factors [31]. The level of economic interests includes: synergetic income distribution, a risk-sharing mechanism and degree of commercialization of research results; management level includes: resource sharing and information exchange, a relationship between the R\&D team and other subjects, and contract breach punishment; and macro environment includes: national environmental regulation, financial institution funds support, intermediary-related services, government policy support and legal and regulatory soundness. Due to the uniqueness of collaborative innovation of low-carbon technology, social low-carbon culture and corporate low-carbon values have a great impact on the diffusion and innovation incentives of low-carbon technology. Thirteen factors are synthesized as shown in Table 2.

Step 2: Determine the direct impact matrix.

50 experts from related fields are invited to do a questionnaire survey on the impact relationship among various factors. The degree of influence was scored on a scale of $0-4, a_{i j}=0$ indicating that the factor $S_{i}$ have no impact $S_{j}, a_{i j}=1$ indicating that the factor $S_{i}$ have little impact $S_{j}, a_{i j}=2$ indicating that the factor $S_{i}$ have a general impact $S_{j}, a_{i j}=3$ indicating that the factor $S_{i}$ have a greater impact $S_{i}$, and $a_{i j}=4$ indicating that the factor $S_{i}$ have a great impact $S_{j}$. The recovery rate of this questionnaire is $100 \%$, and all the collected questionnaires were sorted out to calculate the number of times each situation occurs. The frequency is used as a weight to integrate expert opinions, and then the direct impact matrix A is calculated (see Table 3).

Step 3: Calculate the normal matrix X.

Using Eq. 1, the normal matrix $\mathrm{X}$ is obtained.

$$
X=\frac{1}{\max _{1 \leq i \leq n} \sum_{j=1}^{n} a_{i j}} \cdot A
$$

Step 4: Calculate the comprehensive influence matrix $\mathrm{T}$.

The normal matrix $\mathrm{X}$ is processed according to Eq. 2 in order to obtain the comprehensive influence matrix $\mathrm{T}$, and the calculation results are shown in Table 4 . Where $I$ is the unit matrix and $(I-X)^{-1}$ is the inverse matrix of $(I-X)$.

Table 3. Direct impact matrix A.

\begin{tabular}{|c|c|c|c|c|c|c|c|c|c|c|c|c|c|}
\hline Factor & S1 & S2 & S3 & S4 & S5 & S6 & S7 & S8 & S9 & S10 & S11 & S12 & S13 \\
\hline S1 & 0 & 1 & 1 & 1 & 1 & 4 & 0 & 0 & 0 & 1 & 0 & 0 & 0 \\
\hline S2 & 1 & 0 & 0 & 1 & 1 & 4 & 0 & 0 & 0 & 1 & 0 & 0 & 1 \\
\hline S3 & 2 & 1 & 0 & 1 & 0 & 3 & 0 & 0 & 0 & 0 & 0 & 1 & 1 \\
\hline S4 & 1 & 1 & 1 & 0 & 0 & 3 & 0 & 0 & 0 & 1 & 0 & 1 & 1 \\
\hline S5 & 0 & 1 & 1 & 3 & 0 & 1 & 0 & 0 & 0 & 0 & 0 & 0 & 0 \\
\hline S6 & 1 & 1 & 1 & 1 & 0 & 0 & 1 & 0 & 0 & 1 & 0 & 1 & 1 \\
\hline S7 & 0 & 3 & 0 & 1 & 0 & 1 & 0 & 1 & 1 & 1 & 0 & 1 & 0 \\
\hline S8 & 2 & 0 & 3 & 0 & 0 & 1 & 1 & 0 & 1 & 0 & 0 & 0 & 0 \\
\hline S9 & 3 & 0 & 3 & 0 & 0 & 1 & 0 & 1 & 0 & 0 & 0 & 0 & 0 \\
\hline S10 & 0 & 3 & 0 & 1 & 1 & 1 & 0 & 1 & 1 & 0 & 1 & 1 & 1 \\
\hline S11 & 1 & 0 & 1 & 1 & 0 & 1 & 2 & 1 & 1 & 1 & 0 & 2 & 2 \\
\hline S12 & 1 & 1 & 1 & 1 & 1 & 1 & 3 & 0 & 0 & 2 & 0 & 0 & 3 \\
\hline S13 & 1 & 0 & 3 & 3 & 1 & 1 & 2 & 0 & 0 & 1 & 0 & 2 & 0 \\
\hline
\end{tabular}


Table 4. Comprehensive influence matrix T.

\begin{tabular}{|c|c|c|c|c|c|c|c|c|c|c|c|c|c|}
\hline Factor & S1 & S2 & S3 & S4 & S5 & S6 & S7 & S8 & S9 & S10 & S11 & $\mathrm{S} 12$ & S13 \\
\hline S1 & 188 & 172 & 1841 & 240 & 239 & 161 & 0791 & 0208 & .0208 & 1780 & 0127 & 1031 & 1181 \\
\hline S2 & 1857 & 1535 & 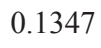 & 3 & 政 & 5170 & 0.0908 & 223 & .0223 & .1862 & 0133 & 11 & .1851 \\
\hline S3 & בת & .2217 & 1 & 0.2397 & 年 & 0.4876 & 0.10 & 0192 & 2 & 9 & 0096 & 3 & 1989 \\
\hline $\mathrm{S} 4$ & 2023 & 0.2318 & תח & 176 & 0.0733 & 0.48 & 0 & 17 & 7 & 94 & 2 & 5 & .2059 \\
\hline S5 & 889 & 640 & 14 & 3024 & 0 & 0.2652 & 0.04 & 0.0102 & 0.0102 & 0.0790 & 0.0056 & 0.0732 & 0.0850 \\
\hline S6 & 1868 & 251 & 0.1907 & 0.2268 & 0.0687 & 0.2675 & 0.1587 & 0.0276 & 0.0276 & 0.1868 & 0.0133 & 0.1739 & 0.1890 \\
\hline S7 & 1408 & 484 & 0.1362 & 0.2138 & 0.0685 & 0.3458 & 0.0857 & 0.0988 & 0.0988 & 0.1851 & 0.0132 & 0.1601 & 0.1240 \\
\hline S8 & 2636 & 0.1280 & 0.3169 & 0.1237 & 0.0464 & 0.3169 & 0.1269 & 0.0221 & 0.0887 & 0.0871 & 0.0062 & 0.0829 & 0.0881 \\
\hline S9 & 3288 & 0.1193 & 0.3201 & 0.1244 & 0.0501 & 0.3282 & 0.0598 & 0.0835 & 0.0169 & 0.0866 & 0.0062 & 0.0791 & 0.0877 \\
\hline $\mathrm{S} 10$ & 1738 & 0.3701 & 0.1836 & 0.2713 & 0.1506 & 0.4047 & 0.1218 & 0.1038 & 0.1038 & 0.1456 & 18 & 0.1 & 0.2233 \\
\hline S11 & 2770 & 0.2447 & 0.2987 & 0.3170 & 0.1006 & 0.4629 & 0.2996 & 0.1209 & 0.12 & 43 & 0.0182 & 0.3084 & 0.3242 \\
\hline S12 & 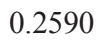 & 0.3425 & 0.2843 & 0.3546 & 0.1788 & 19 & 0.3 & 0. & 0. & 76 & 34 & 0.1879 & 0.3865 \\
\hline S13 & 0.2693 & 0.2656 & 0.3993 & 0.4578 & 0.1648 & 0.5023 & 0.2800 & 0.0428 & 0.0428 & 0.2584 & 0.0185 & 0.3101 & 0.2036 \\
\hline
\end{tabular}

$$
\begin{aligned}
T & =\left(t_{i j}\right)_{n \times n}=\lim _{l \rightarrow \infty}\left(X^{1}+X^{2}+\cdots+X^{l}\right) \\
& =\lim _{l \rightarrow \infty} X\left[\frac{I-X^{l}}{I-X}\right]=X(I-X)^{-1}
\end{aligned}
$$

Step 5: Calculate the influence degree $f_{i}$, affected degree $e_{i}$, center degree $M_{i}$ and cause degree $N_{i}$ of each factor.

According to Eqs. 3-6, the calculation results are shown in Table 5.

The influence degree indicates the comprehensive influence degree of this element on all other elements:

$$
f_{i}=\sum_{j=1}^{n} t_{i j}, i=1,2 \cdots n
$$

The influence degree indicates that the element is affected by all other factors:

$$
e_{i}=\sum_{j=1}^{n} t_{j i}, i=1,2 \cdots n
$$

The center degree indicates how important this factor is in the system:

$$
M_{i}=f_{i}+e_{i}, i=1,2 \cdots n
$$

$N_{j}>0$, which means that this element has greater influence on other factors, is called the reason factor. $N_{j}<0$, which means that the element is greatly affected by other factors, is called the result factor.

$$
N_{i}=f_{i}-e_{i}, i=1,2 \cdots n
$$

Step 6: Draw a Cartesian coordinate system with the center degree as the abscissa and the cause degree as the ordinate, and make a comparative analysis through the relative distribution of each factor in the Cartesian coordinate system, as shown in Fig. 6.

Table 5. Influence degree, affected degree, center degree and cause degree.

\begin{tabular}{|c|c|c|c|c|c|c|c|c|c|}
\hline Factor & $f_{i}$ & $e_{i}$ & $M_{i}$ & $N_{i}$ & Factor & $f_{i}$ & $e_{i}$ & $M_{i}$ & $N_{i}$ \\
\hline S1 & 1.9167 & 2.7601 & 4.6768 & -0.8434 & $\mathrm{~S} 8$ & 1.6974 & 0.6508 & 2.3482 & 1.0466 \\
\hline S2 & 1.9916 & 3.0320 & 5.0235 & -1.0404 & $\mathrm{~S} 9$ & 1.6906 & 0.6508 & 2.3414 & 1.0398 \\
\hline S3 & 2.0927 & 2.9451 & 5.0378 & -0.8523 & $\mathrm{~S} 10$ & 2.5296 & 2.3089 & 4.8385 & 0.2207 \\
\hline S4 & 2.1336 & 3.2701 & 5.4037 & -1.1365 & $\mathrm{~S} 11$ & 3.1475 & 0.2363 & 3.3839 & 2.9112 \\
\hline S5 & 1.3163 & 1.2624 & 2.5786 & 0.0539 & $\mathrm{~S} 12$ & 3.2968 & 2.1526 & 5.4495 & 1.1442 \\
\hline S6 & 1.9425 & 5.3864 & 7.3290 & -3.4439 & $\mathrm{~S} 13$ & 3.2154 & 2.4195 & 5.6349 & 0.7959 \\
\hline S7 & 2.0189 & 1.9148 & 3.9337 & 0.1042 & & & & & \\
\hline
\end{tabular}




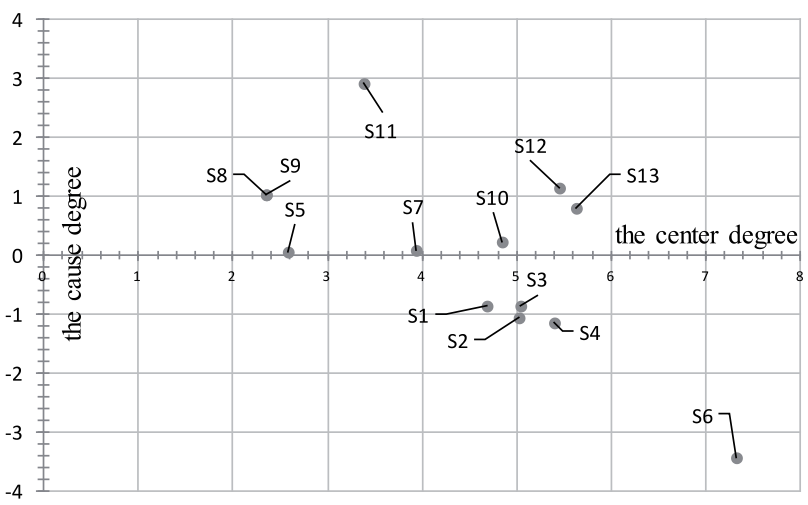

Fig. 6. Causality Diagram.

The calculated causality diagram shows that contract breach punishment (S6) is the most central of all factors and plays a vital role in the collaborative innovation of low-carbon technology in IURG. Relations between R\&D team and other subjects (S5), national environmental regulation (S7), financial institution funds support (S8), intermediary-related services (S9), government policy support (S10), legal and regulatory soundness (S11), low-carbon consciousness and culture (S12) and an enterprise's value of low-carbon technology innovation (S13) are all above the abscissa, called reason factor. The other five factors are negative and are called the result factor.

The cause degree of legal and regulatory soundness (S11) is the highest, indicating that this factor has the strongest influence on other factors and should be the most concerned issue in the innovation process of IURG. The cause degree of contract breach punishment (S6) is the lowest, indicating that this factor is most affected by other factors. In a word, to create a good low-carbon economic atmosphere, to formulate reasonable laws and regulations, to provide a more perfect cooperation platform for social intermediaries and financial institutions, and to determine a reasonable income distribution ratio and risk sharing mechanism are important measures to the cooperative innovation of low-carbon technology in IURG.

Step 7: Establish reachability matrix. The reachability matrix represents the "arrival" relationship between elements.

According to the comprehensive influence matrix, add the influence of its own factors to get the overall influence matrix:

$$
H=T+I=\left(h_{i j}\right)_{n \times n}
$$

The calculation formula of reachable matrix $M=\left(m_{i j}\right)$ is as follows:

$$
m_{i j}=\left\{\begin{array}{l}
1, h_{i j} \geq \lambda \\
0, h_{i j}<\lambda
\end{array}\right.
$$

The threshold $\lambda$ affects the composition and hierarchy of the subsequent reachable matrix, and the value of $\lambda$, which is determined by expert decision makers to obtain the most satisfactory result. After many discussions and verification with experts, the threshold $\lambda=0.24$ is determined in this paper, and finally the reachable matrix $\mathrm{M}$.

Step 8: Factor level division.

Reachable set $R\left(S_{i}\right)$ means a set of all the influencing factors that can be reached from the influencing factor $m_{i}$.

Antecedent set $A\left(S_{i}\right)$ represents a set of all the factors that can reach the influencing factor $m_{i}$.

According to Eqs. 9 and 10, we can obtain $R\left(S_{i}\right)$ and $A\left(S_{i}\right)$ :

$$
\begin{aligned}
& R\left(S_{i}\right)=\left\{S_{j} \mid m_{i j}=1\right\} \\
& A\left(S_{i}\right)=\left\{S_{j} \mid m_{j i}=1\right\}
\end{aligned}
$$

By calculating the intersection of $R\left(S_{i}\right)$ and $A\left(S_{i}\right)$, the first set of influencing factors can be obtained $L_{1}$ by using Eq. (11):

\begin{tabular}{|c|c|c|c|}
\hline $\begin{array}{l}\text { Influence } \\
\text { factor }\end{array}$ & $\mathrm{R}(\mathrm{Si})$ & $\mathrm{A}(\mathrm{Si})$ & $\mathrm{R} \cap \mathrm{A}$ \\
\hline S1 & S1, S6 & $\begin{array}{l}\mathrm{S} 1, \mathrm{~S} 3, \mathrm{~S} 8, \mathrm{~S} 9, \\
\mathrm{~S} 11, \mathrm{~S} 12, \mathrm{~S} 13\end{array}$ & S1 \\
\hline S2 & S2, S6 & $\begin{array}{l}\text { S2, S6, S7, S11, } \\
\text { S12, S13 }\end{array}$ & S2 \\
\hline $\mathrm{S} 3$ & S1, S3, S6 & $\begin{array}{l}\text { S3, S8, S9, S11, } \\
\text { S12, S13 }\end{array}$ & S3 \\
\hline S4 & S4, S6 & $\mathrm{S} 4, \mathrm{~S} 10, \mathrm{~S} 11, \mathrm{~S} 12$ & S4 \\
\hline S5 & S4, S5, S6 & S5 & S5 \\
\hline S6 & S6 & $\begin{array}{c}\text { S1, S2, S3, S4, S6, } \\
\text { S7, S8, S9, S11, } \\
\text { S12, S13 }\end{array}$ & S6 \\
\hline S7 & $\mathrm{S} 2, \mathrm{~S} 6, \mathrm{~S} 7$ & S7, S11, S12, S13 & S7 \\
\hline S8 & S1, S3, S6, S8 & S8 & S8 \\
\hline S9 & S1, S3, S6, S9 & S9 & S9 \\
\hline S10 & $\mathrm{S} 2, \mathrm{~S} 6, \mathrm{~S} 10$ & $\begin{array}{l}\text { S10, } \mathrm{S} 11, \mathrm{~S} 12, \\
\mathrm{~S} 13\end{array}$ & $\mathrm{~S} 10$ \\
\hline S11 & $\begin{array}{l}\text { S1, S2, S3, S4, S6, } \\
\text { S7, S10, S11, S12, } \\
\text { S13 }\end{array}$ & S11 & $\mathrm{S} 11$ \\
\hline S12 & $\begin{array}{l}\text { S1, S2, S3, S4, S6, } \\
\text { S7, S10, S12, S13 }\end{array}$ & $\mathrm{S} 11, \mathrm{~S} 12, \mathrm{~S} 13$ & $\begin{array}{l}\mathrm{S} 12 \\
\mathrm{~S} 13\end{array}$ \\
\hline S13 & $\begin{array}{l}\text { S1, S2, S3, S4, S6, } \\
\text { S7, S10, S12, S13 }\end{array}$ & $\mathrm{S} 11, \mathrm{~S} 12, \mathrm{~S} 13$ & $\begin{array}{l}\mathrm{S} 12 \\
\mathrm{~S} 13\end{array}$ \\
\hline
\end{tabular}

$$
L_{1}=\left\{S_{i} \mid C\left(S_{i}\right)=R\left(S_{i}\right)\right\}
$$

Table 6. Relationships among influencing factors. 
Table 7. Rearranged reachability matrix $\mathrm{M}$.

\begin{tabular}{|c|c|c|c|c|c|c|c|c|c|c|c|c|}
\hline Factor & S6 & S1 & S2 & S4 & S5 & S3 & S10 & S7 & S8 & S9 & S12 & S11 \\
\hline S6 & 1 & 0 & 0 & 0 & 0 & 0 & 0 & 0 & 0 & 0 & 0 & 0 \\
\hline S1 & 1 & 1 & 0 & 0 & 0 & 0 & 0 & 0 & 0 & 0 & 0 & 0 \\
\hline S2 & 1 & 0 & 1 & 0 & 0 & 0 & 0 & 0 & 0 & 0 & 0 & 0 \\
\hline S4 & 1 & 0 & 0 & 1 & 0 & 0 & 0 & 0 & 0 & 0 & 0 & 0 \\
\hline S5 & 1 & 0 & 0 & 1 & 1 & 0 & 0 & 0 & 0 & 0 & 0 & 0 \\
\hline S3 & 1 & 1 & 0 & 0 & 0 & 1 & 0 & 0 & 0 & 0 & 0 & 0 \\
\hline S10 & 1 & 0 & 1 & 0 & 0 & 0 & 1 & 0 & 0 & 0 & 0 & 0 \\
\hline S7 & 1 & 0 & 1 & 0 & 0 & 0 & 0 & 1 & 0 & 0 & 0 & 0 \\
\hline S8 & 1 & 1 & 0 & 0 & 0 & 1 & 0 & 0 & 1 & 0 & 0 & 0 \\
\hline S9 & 1 & 1 & 0 & 0 & 0 & 1 & 0 & 0 & 0 & 1 & 0 & 0 \\
\hline S12 & 1 & 1 & 1 & 1 & 0 & 1 & 1 & 1 & 0 & 0 & 1 & 0 \\
\hline S11 & 1 & 1 & 1 & 1 & 0 & 1 & 1 & 1 & 0 & 0 & 1 & 1 \\
\hline
\end{tabular}

The factors in $L_{1}$ have the following characteristics: other influencing factors can reach this factor, but this factor cannot reach other factors. So, the influencing factors in $L_{1}$ are at the highest level.

The first level factor set $L_{1}=\{S 3\}$. Then remove the elements in $L_{1}$ to obtain the second layer factor set $L_{2}=\{S 1, S 2, S 4\}$, and repeat this step to obtain the third layer factor set $L_{3}=\{S 13, S 5, S 6, S 7\}$, the fourth layer factor set $L_{4}=\{S 8, S 9, S 10, S 12\}$, and the fifth layer factor set $L_{5}=\{S 11\}$. The specific results are shown in Table 6.

Table 6 shows that S12 and S13 play the same role in the whole system. Therefore, only S12 is retained in the subsequent calculation. The rearranged reachable matrix $\mathrm{M}$ is obtained by adjusting the rows and columns of $\mathrm{M}$ according to the number of " 1 " elements in each row. Finally, in the rearranged reachable matrix $M$, the unit matrix of the largest order is decomposed from the upper left corner to the lower right corner, and the box is added. Each box represents a level. The specific results are shown in Table 7.

Step 9: Construct a hierarchical structure diagram.

According to the relationship between the hierarchical results and the elements, a corresponding explanatory structure model diagram can be drawn in which the box represents the model elements and the arrow represents the influence relationship between the model elements. The model diagram expresses the structure of the influencing factors of the whole cooperative innovation system of low-carbon technology in the industry-university-research government. According to the above analysis results, an explanation structure model of the system can be constructed, as shown in Figs 7 and 8.

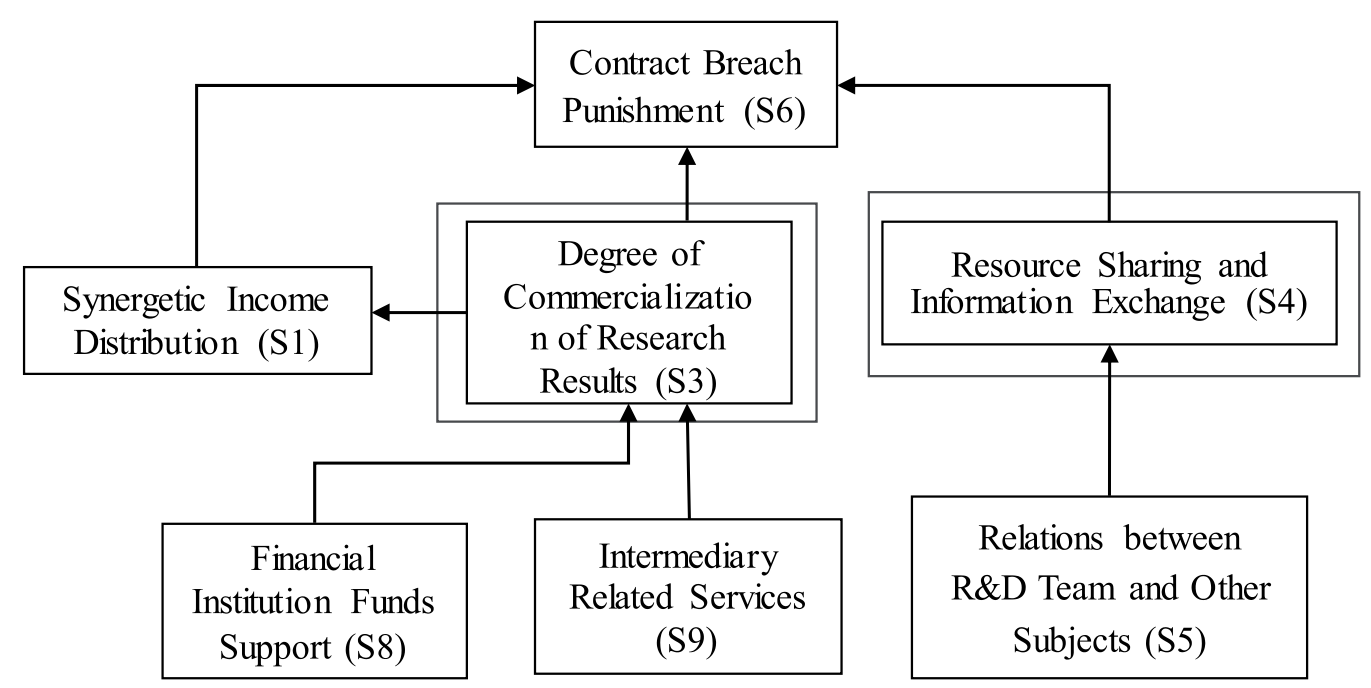

Fig. 7. Explanatory Structural Model of Influencing Factors of Cooperative Innovation of IURG.1. 


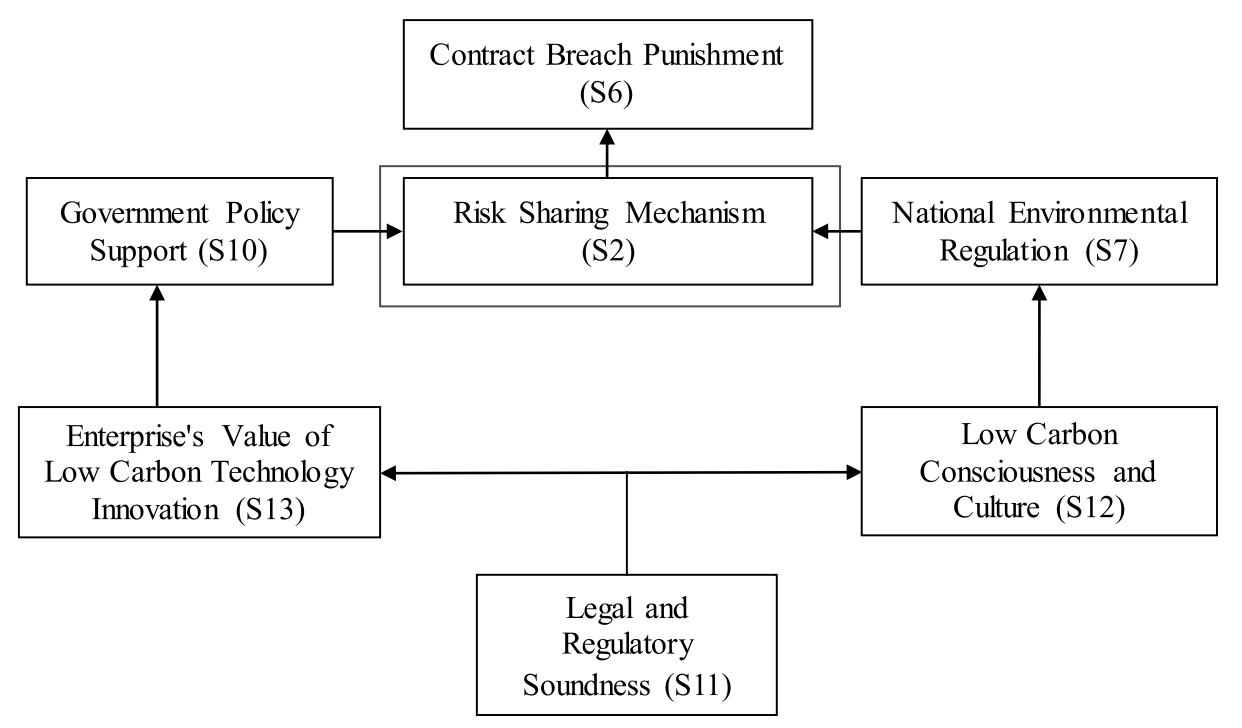

Fig. 8. Explanatory Structural Model of Influencing Factors of Cooperative Innovation of IURG.2.

Fig. 7 shows two chains of the influencing factor explanatory structure model. One of the chains is that the intermediary related services and financial institutions founds support affect degree of commercialization of research results and further affect the synergetic income distribution and contract breach punishment; the other is that relations between the R\&D team and other subjects affects resource sharing and information exchange, which further affects contract breach punishment. In Fig. 7, the degree of commercialization of research results and the resource sharing and information exchange are two important factors in the explanatory structural model.

Fig. 8 shows the structural model of influencing factors at the macro-environmental level. On the one hand, there are soft influencing factors of corporate low-carbon values and social low-carbon culture; on the other hand, there are government policy support, the degree of perfection of laws and regulations and the hard influencing factors of national environmental regulation. These five factors affect the risk-sharing mechanism, and further affect the penalty for breach of contract. The risk-sharing mechanism in Figure 8 is an important factor in the macro-impact interpretation structure model.

\section{Conclusions}

Thirteen factors influencing the collaborative innovation of low-carbon technology in IURG form the explanatory structure model.

First of all, Contract Breach Punishment (S6) has the most direct impact on the success of the cooperative innovation of low-carbon technology in IURG. After the contract is reached, both parties are willing to cooperate and innovate together for a long time. However, with the changes in the external environment of low-carbon technology innovation, there will inevitably be a shift of strategic focus or a change in business philosophy, which will cause the management to abandon the continuous innovation of low-carbon technology. In another case, both parties need to share and exchange knowledge and technology in the process of collaborative innovation. It is possible that one party, after acquiring the other party's key technologies, will go against the contract to develop and acquire the profits alone. If the punishment for breach of contract is relatively strong and even exceeds the total revenue generated after breach of contract, then all participants will continue to cooperate in innovation and give up the benefit temptation brought by opportunism. Therefore, the provisions on penalties for breach of contract in the contract need to be as detailed as possible and the penalties should be increased. This can effectively avoid the breakdown of the cooperation innovation of low-carbon technology in IURG.

Secondly, the middle-tier factors that affect the cooperation innovation of low-carbon technology in IURG include synergetic income distribution (S1), a risk-sharing mechanism (S2), resource sharing and information exchange (S4), degree of commercialization of research results (S3), government policy support (S10) and national environmental regulation (S7). The purpose of low-carbon technology collaborative innovation is to obtain benefits. The scientific treatment of the interest issue and the satisfactory income distribution plan are important steps for the success of the cooperation innovation of low-carbon technology in IURG. However, among the many indicators that affect the distribution of benefits, the risk taking by different subjects is one of the most important factors to be considered. First, we should clarify the respective responsibilities and obligations of both parties, and then design the cooperative income distribution plan corresponding to the risk-taking. 
The R\&D team is the main body of innovation in university scientific research institutions. However, the relationship between organization and team also affects the coordination of innovation technology. The frequency of communication affects the degree of trust, and the degree of trust affects the depth of collaboration. Frequent and effective communication can resolve contradictions by information asymmetry, remove obstacles caused by differences in values, make the two sides more closely connected and strengthen mutual trust. When the IURG has a high degree of trust, low-carbon technology and knowledge will be fully exchanged, resources will be most efficiently integrated, and the success rate of low-carbon technology innovation will be greatly improved. The low-carbon technology will eventually be applied to the production process. Whether it can be commercialized smoothly and profitably will have an important impact on enterprises. Accelerating the transformation of achievements and realizing the market value of new achievements can ensure the willingness and enthusiasm of enterprises to innovate low-carbon technologies. Because of the high risks that innovation needs to face, the government's policy guidance and macro-control measures will play a strong role. On the one hand, it is an incentive measure to subsidize the cooperative innovation of low-carbon technologies. On the other hand, the government imposed environmental taxes on enterprises and implemented environmental regulatory measures such as carbon emissions trading. All these government actions have a very important impact on promoting the innovation of low-carbon technologies in IURG.

Finally, legal and regulatory soundness (S11) is at the bottom of the explanatory structure model, as well as financial institution funds support (S8), intermediaryrelated services (S9), low-carbon consciousness and culture (S12), and an enterprise's value of low-carbon technology innovation (S13) - which are overall factors affecting the cooperative innovation of low-carbon technology in IURG. Financial institutions can solve the difficulty of low-carbon technological innovation due to lack of funds. At the same time, information consulting and technology evaluation services provided by intermediaries effectively promote communication and cooperation between IURG. The perfection of laws and regulations on cooperative innovation not only improves the government's macro-control efforts, but also scientifically and reasonably solves the conflicts of interests in IURG.

To sum up the above four conclusions, we will make the conclusions more abstract and universal from the three levels of economic interest, management and macro environment of these 13 factors. The level of economic interest: the participants of low-carbon technological innovation are all aiming at gaining benefits. Reasonable benefits, reasonable risk sharing, reasonable rewards and punishments and efficient transformation of low-carbon technological achievements will motivate participants.
The level of management: good relationship between participants, perfect information exchange platform and convenient resource interaction channels will reduce the management risk caused by information asymmetry. The level of macroscopic environment: there are soft factors affecting corporate low-carbon values and social low-carbon culture, as well as government policy support, the degree of sound laws and regulations and hard factors affecting national environmental regulation, and intermediaries and financial institutions to help reduce barriers to low-carbon technological innovation.

Through the in-depth study of 13 influencing factors of economic interests, management and macro environment, our research results not only help to promote the development of existing literature, but also have special significance for collaborative innovation managers and low-carbon policy makers.

\section{Acknowledgements}

The authors sincerely acknowledge financial support from the Hebei Provincial Science and Technology Department's Innovation Capability Improvement Program (No. 18456214D).

\section{Conflict of Interest}

The authors declare no conflict of interest.

\section{References}

1. ZHANG L., SOVACOOL B.K., REN J.Z., ELY A. The Dragon awakens: Innovation, competition, and transition in the energy strategy of the People's Republic of China, 1949-2017. Energy Policy, 108, 634, 2017. https://doi. org/10.1016/j.enpol.2017.06.027.

2. FARALLI M., GROVE I.G., HARE M.C., KETTLEWELL P.S., FIORANI F. Rising $\mathrm{CO}_{2}$ from historical concentrations enhances the physiological performance of Brassica napus seedlings under optimal water supply but not under reduced water availability. Plant Cell and Environment, 40, 317, 2017. https://doi.org/10.1111/ pce. 12868.

3. SU J.Z., WEN M., DING Y., GAO Y.Q., SONG Y.F. Hiatus of Global Warming: A Review. Chinese Journal of Atmospheric Sciences, 40, 1143, 2016. Doi:10.3878/j. issn.1006-9895.1512.15242.

4. MA M.D., SHEN L.Y., REN H., CAI W.G., MA Z.L. How to measure carbon emission reduction in China's public building sector: retrospective decomposition analysis based on STIRPAT model in 2000-2015. Sustainability, 9, 1744, 2017. https://doi.org/10.3390/su9101744.

5. BP Statistical Review of World Energy, 2018. https:// www.bp.com/content/dam/bp-country/zh_cn/ Publications/2018SRbook.pdf.

6. DONG F., YU B.L., HADACHIN T., DAI Y.J., WANG Y., ZHANG S.N., LONG R.Y. Drivers of carbon emission intensity change in China. Resources, Conservation 
and Recycling, 129, 187, 2018. https://doi.org/10.1016/j. resconrec.2017.10.035.

7. DONG F., WANG Y., SU B., HUA Y.F., ZHANG Y.Q. The process of peak $\mathrm{CO}_{2}$ emissions in developed economies: A perspective of industrialization and urbanization. Resources, Conservation and Recycling, 141, 61, 2019. https://doi.org/10.1016/j.resconrec.2018.10.010.

8. DONG F., BIAN Z.F., YU B.L., WANG Y., ZHANG S.N., LI J.Y., SU B., LONG R.Y. Can land urbanization help to achieve $\mathrm{CO}_{2}$ intensity reduction target or hinder it? Evidence from China. Resources, Conservation and Recycling, 134, 206, 2018. https://doi.org/10.1016/j. resconrec.2018.02.009.

9. CHEN J., SHEN L., SONG X., SHI Q., LI S. An empirical study on the $\mathrm{CO} 2$ emissions in the Chinese construction industry. Journal of Cleaner Production, 168, 645, 2017. https://doi.org/10.1016/j.jclepro.2017.09.072.

10. URBAN F. China's rise: Challenging the North-South technology transfer paradigm for climate change mitigation and low carbon energy. Energy Policy, 113, 320, 2018. https://doi.org/10.1016/j.enpol.2017.11.007.

11. RASMUS L., MICHIKO I., RAINER W. Introduction to low-carbon innovation and development: insights and future challenges for research. Innovation and Development, 5, 173, 2015. https://doi.org/10.1080/215793 0X.2015.1065096.

12. KIRCHHERR J., URBAN F. Technology transfer and cooperation for low carbon energy technology: Analysing 30 years of scholarship and proposing a research agenda. Energy Policy, 119, 600, 2018. https://doi.org/10.1016/j. enpol.2018.05.001.

13. LIU J.H., PU J.M., JIANG Z.H. Promoting Strategy of New Energy Vehicles Collaborative Innovation: The Case Study of Yutong. Procedia Engineering, 174, 1009, 2017. https://doi.org/10.1016/j.proeng.2017.01.253.

14. YIN S., LI B.Z. A stochastic differential game of low carbon technology sharing in collaborative innovation system of superior enterprises and inferior enterprises under uncertain environment. Open Mathematics, 16, 607, 2018. https://doi.org/10.1515/math-2018-0056.

15. FENG L., ZHANG X.H. ZHOU K.G. Current problems in China's manufacturing and countermeasures for industry 4.0. EURASIP Journal on Wireless Communications and Networking, 90, 2018. https://doi.org/10.1186/s13638-0181113-6.

16. ZHAO J.Y. WU G.D. Evolution of the Chinese IndustryUniversity-Research Collaborative Innovation System. Complexity, 9, 2017. https://doi.org/10.1155/2017/4215805.

17. WANG X., FANG H., ZHANG F., FANG SR. The Spatial Analysis of Regional Innovation Performance and Industry-University-Research Institution Collaborative Innovation - An Empirical Study of Chinese Provincial Data. Sustainability, 10 (4), 1243, 2018. https:/doi. org/10.3390/su10041243.

18. ALBATS E., FIEGENBAUM I., CUNNINGHAM J.A. A micro level study of university industry collaborative lifecycle key performance indicators. The Journal of Technology Transfer, 43 (2), 389, 2018. DOI: 10.1007/ s10961-017-9555-2.

19. MILLER K., MCADAM R., MCADAM M. A systematic literature review of university technology transfer from a quadruple helix perspective: toward a research agenda. R\&D Management, 48 (1), 7, 2018. DOI: 10.1111/ radm. 12228 .

20. VILLASANA M. Fostering university-industry interactions under a triple helix model: the case of Nuevo
Leon, Mexico. Science and Public Policy, 38 (1), 43, 2011. https://doi.org/10.3152/030234211X12924093659996.

21. VEUGELERS R., CASSIMAN B. R\&D cooperation between firms and universities. Some empirical evidence from Belgian manufacturing. International Journal of Industrial Organization, 23, 355, 2005. https://doi. org/10.1016/j.ijindorg.2005.01.008.

22. AGUSTÍ S.B., JOSEP-MARIA A.C. Sources of innovation and industry-university interaction:Evidence from Spanish firms. Research Policy, 37, 1283, 2008.https:/doi. org/10.1016/j.respol.2008.05.003.

23. QIU X.F., ZHANG Y.Q. Analysis of Influencing Factors of Industry-University-Research Collaboration Innovation and Countermeasures. Chinese University Science \& Technology, 48, 2016. DOI:10.16209/j.cnki.cust.2016. Z1.016.

24. LIU Z.Y. Analysis of the Influence Factors of College Students Employment Based on the Interpretative Structural Model. EURASIA Journal of Mathematics, Science and Technology Education, 13 (8), 5107, 2017. https://doi.org/10.12973/eurasia.2017.01007a.

25. CHANG Q.J., WANG L., JING H.M. Research on Internal Control Innovation Based on DEMATEL and ISM. Friends of Accounting, 8, 80, 2016.

26. QIN S.S. Research on Internal Control Innovation Based on DEMATEL and ISM. Value Engineering, 2, 91, 2018. DOI:10.14018/j.cnki.cn13-1085/n.2018.02.036.

27. SHEN G.X., SUN S.G., ZHANG Y.Z., WANG Z.Q., CHEN B.K., MA C. System failure analysis based on DEMATEL-ISM and FMECA. Journal of Central South University, 21 (12), 4518, 2014. https://doi.org/10.1007/ s11771-014-2456-8.

28. SHEN J.F., LI F.Y., SHI D., LI H.Z., YU X.H. Factors Affecting the Economics of Distributed Natural GasCombined Cooling, Heating and Power Systems in China: A Systematic Analysis Based on the Integrated Decision Making Trial and Evaluation Laboratory-Interpretative Structural Modeling (DEMATEL-ISM) Technique. Energies, 11 (9), 2318, 2018. https://doi.org/10.3390/ en11092318.

29. ZHOU X.Y., SHI Y.Q.Y., DENG X.Y., DENG Y. D-DEMATEL: A new method to identify critical success factors in emergency management. Safety Science, 91, 93, 2017. https://doi.org/10.1016/j.ssci.2016.06.014.

30. ZHANG P.K., LUO F. Influencing Factors of Runway Incursion Risk and Their Interaction Mechanism Based on DEMATEL-ISM. Tehnicki Vjesnik-Technical Gazette, 24, 1853, 2017. https://doi.org/10.17559/TV-0170928105858.

31. ZHAO H.F., ZHANG X .W., JIA F.L. Influencing Factors of Collaborative Innovation in Industry, University and Research Institute and Its Impact on Innovation Performance--Based on Empirical Research in Hebei Province. Science Technology and Industry, 3, 57, 2018.

32. MALIK K., GEORGHIOU L., GRIEVE B. Developing New Technology Platforms for New Business Models: Syngenta's Partnership with the University of Manchester. Research-Technology Management, 54, 24, 2011. https:// doi.org/10.1080/08956308.2011.11657670.

33. HU J.Y., ZHU G.L., MA, Y.Y. System Dynamic Analysis on Influencing Factors of Industry-University-Research Cooperation in Open Innovation Context. Science of Science and Management of S. \& T., 8, 49, 2011.

34. HUANG J.J. Research on the University - industry Collaborative Innovation Efficiency and Its Affecting Factors. Soft Science, 5, 38, 2017. DOI:10.13956/j.ss10018409.2017.05.09. 
35. FREITAS I.M.B., GEUNA A., ROSSI F. Finding the right partners: Institutional and personal modes of governance of university-industry interactions. Research Policy, 42, 50, 2013. https://doi.org/10.1016/j.respol.2012.06.007.

36. MORA-VALENTIN E.M., MONTORO-SANCHEZ A., GUERRAS-MARTIN L.A. Determining factors in the success of R\&D cooperative agreements between firms and research organizations. Research Policy, 33, 17, 2004. https://doi.org/10.1016/S0048-7333(03)00087-8.

37. FOGELBERG H., THORPENBERG S. Regional innovation policy and public-private partnership: The case of Triple Helix Arenas in Western Sweden. Science and Public Policy, 39, 347, 2012. https://doi.org/10.1093/scipol/ $\operatorname{ses} 023$.
38. LAI W.H. Willingness-to-engage in technology transfer in industry-university collaborations. Journal of Business Research, 64, 1218, 2011. https://doi.org/10.1016/j. jbusres.2011.06.026.

39. D'ESTE P., PATEL P. University-industry linkages in the UK: What are the factors underlying the variety of interactions with industry? Research Policy, 36, 1295, 2007. https://doi.org/10.1016/j.respol.2007.05.002.

40. HEMMERT M., BSTIELER L., OKAMURO H. Bridging the cultural divide: Trust formation in university-industry research collaborations in the US, Japan, and South Korea. Technovation, 34, 605, 2014. https://doi.org/10.1016/j. technovation.2014.04.006. 